\title{
Formação contínua centrada na escola e currículo do mar - o caso de uma escola inaciana
}

\section{School-based teacher training and sea curriculum - an Ignatian school case}

\author{
Pedro Ribeiro Mucharreira*
}

\begin{abstract}
RESUMO
O presente artigo apresenta resultados parciais de uma investigação em torno do papel da formação contínua centrada na escola, no desenvolvimento profissional docente. A investigação decorreu numa escola privada nos arredores de Lisboa, em Portugal. Neste trabalho são apresentados os resultados da recolha e análise documental que permitiu caracterizar a política de formação da escola, organização que se estrutura num projeto educativo de inspiração inaciana e num currículo do mar que procura promover uma constante interdisciplinaridade. As principais conclusões da investigação apontam no sentido de um efetivo estabelecimento de uma comunidade de aprendizagem, que reflete na e sobre a prática, para além de a política de formação se encontrar em estreita articulação com o projeto educativo.
\end{abstract}

Palavras-chave: Formação de professores. Formação centrada na escola. Desenvolvimento profissional docente. Pedagogia Inaciana.

\begin{abstract}
This research presents the partial data from a research focusing the role of school-based teacher training in the teacher professional development. The investigation occurred in a private school on the outskirts of Lisbon, in Portugal. This paper presents the results from the data collection that allowed to characterize the teacher training policy of the school, scholar organization that is structured in an educational project of Ignatian inspiration and in

* Instituto de Educação, Universidade de Lisboa. Lisboa, Portugal. E-mail: prmucharreira@ ie.ulisboa.pt. https://orcid.org/0000-0003-0059-0576.
\end{abstract}


a sea curriculum that seeks to promote a constant interdisciplinarity. The main conclusions of this study point towards an effective establishment of a community learning that reflects in and over the practice. In addition, the teacher training policy is closely linked to the educational project.

Keywords: Teacher Training. School-Based Teacher Training. Teacher Professional Development. Ignatian Pedagogy.

\section{Introdução}

Os desafios que se colocam atualmente aos professores são cada vez mais diversificados e complexos, originando uma necessidade crescente de formação destes profissionais. A formação de professores continua a ser uma temática que suscita grande interesse em Portugal e no mundo, não apenas em um âmbito escolar e académico, mas em um plano mais alargado, ao nível político, económico e social, sendo encarada como um fator crítico de sucesso tendo em vista a procura do sucesso educativo (HILTON; FLORES; NIKLASSON, 2013).

O presente artigo, que parte de uma breve caracterização da formação contínua de professores em Portugal, baseia-se numa investigação em torno do papel da formação contínua de professores, centrada na escola, no desenvolvimento profissional docente e no próprio projeto educativo da escola. Recorrendo-se a um estudo de caso, através de notas de campo, recolha e análise documental e entrevistas semiestruturadas a diferentes atores educativos, a investigação pretendeu obter resultados que evidenciassem as possíveis relações entre as políticas de formação contínua, centradas na escola, e as outras dimensões em estudo - o projeto educativo e o desenvolvimento profissional dos professores. Neste artigo são apresentados apenas os resultados da recolha e análise documental, pretendendo-se caracterizar a política formativa da organização escolar em estudo.

\section{Formação contínua de professores}

A formação de professores, na sua generalidade, continua a ser encarada como um importante fator, entre outros, no sentido de promover o sucesso educativo, medido em última instância pela melhoria na aprendizagem dos 
alunos (MUCHARREIRA, 2017). Apesar de nos últimos anos estar disponível um significativo número de investigações na área da formação contínua de professores, particularmente em Portugal, a generalidade da produção científica coloca o enfoque na formação da iniciativa dos centros de formação, vulgarmente conhecidos no contexto português por Centros de Formação de Associação de Escolas (CFAE), do que propriamente na formação contínua da iniciativa das escolas, e dos seus efeitos em contextos escolares específicos.

Os CFAE surgiram em Portugal na década de 90, e encontram-se atualmente regulados pelo Decreto-lei n. ${ }^{\circ}$ 127/2015 de 7 de julho, estipulando que estes se encontram orientados para o desenvolvimento profissional, a atualização científica e pedagógica dos professores, tendo em vista a melhoria do ensino e um incremento dos níveis de eficácia nos processos de governança das escolas (MUCHARREIRA; CABRITO; CERDEIRA, 2018). Paralelamente, é de realçar que estas ações de formação promovidas pelos CFAE têm associada a questão da progressão na carreira docente. Desta forma, a possibilidade de progressão ou não na carreira está dependente da atribuição de créditos pela frequência e respetivo aproveitamento nestas ações de formação.

Segundo Canário (1994), os CFAE conquistaram uma rápida implantação preocupando-se em tentar transferir as formações para os contextos específicos das escolas. Contudo, segundo o autor, a formação disponibilizada por estes centros foi sempre generalista e tendencialmente distante da realidade das escolas e das reais necessidades dos docentes. Apesar das fragilidades descritas, a formação disponibilizada nos CFAE foi contribuindo para o incremento da reflexão e profissionalidade docentes (CANÁRIO, 2005).

A investigação em Portugal não tem, assim, acompanhado uma tendência notória a nível internacional de procurar compreender melhor o papel que uma formação contínua centrada na escola possa ter no desenvolvimento profissional dos docentes. Oportunidades estas que, segundo Forte e Flores (2014), trarão benefícios para a prática docente e porventura para a própria organização escolar. Através do Quadro 1 torna-se possível constatar a evolução, no sistema educativo português, das modalidades de formação em que se estruturaram as ações formativas disponibilizadas pelas diferentes entidades acreditadas pelo Conselho Científico-Pedagógico da Formação Contínua (CCPFC). 
QUADRO 1 - EVOLUÇÃO DA DISTRIBUIÇÃO PERCENTUAL DE AÇÕES POR MODALIDADE DE FORMAÇÃO

\begin{tabular}{|c|c|c|c|c|c|c|c|c|c|c|}
\hline Modalidades & $\mathbf{2 0 0 8}$ & $\mathbf{2 0 0 9}$ & $\mathbf{2 0 1 0}$ & $\mathbf{2 0 1 1}$ & $\mathbf{2 0 1 2}$ & $\mathbf{2 0 1 3}$ & $\mathbf{2 0 1 4}$ & $\mathbf{2 0 1 5}$ & $\mathbf{2 0 1 6}$ & $\mathbf{2 0 1 7}$ \\
\hline Curso de Formação & 31,1 & 64,6 & 56,6 & 59,4 & 61,1 & 72,7 & 63,9 & 73,7 & 71,1 & 55,7 \\
\hline Módulo de Formação & 16,9 & 2,1 & 2,3 & 3,2 & 1,9 & 0,9 & 2,1 & 0,2 & 0 & 0 \\
\hline Disciplinas Singulares & - & 1,5 & 8,2 & 0,4 & 4,8 & 1,2 & 1 & 0,6 & 0,7 & 1 \\
\hline Seminário & 0,4 & 0,2 & 0,2 & 0,9 & 0,1 & 0,1 & 0,1 & 0 & 0 & 0,1 \\
\hline Oficina de Formação & 45,3 & 29,5 & 27,7 & 30,7 & 28,4 & 22,5 & 30,7 & 22,8 & 26,3 & 41,9 \\
\hline Estágio & 0,2 & 0,1 & 0,2 & 0,1 & 0,1 & 0,1 & 0 & 0,1 & 0 & 0 \\
\hline Projeto & 1 & 0,6 & 3,1 & 3,6 & 1,9 & 1,1 & 0,8 & 0,5 & 0,5 & 0,2 \\
\hline Círculo de Estudos & 5,1 & 1,5 & 1,9 & 1,7 & 1,7 & 1,5 & 1,3 & 2,1 & 1,4 & 1,1 \\
\hline Total & $\mathbf{1 0 0}$ & $\mathbf{1 0 0}$ & $\mathbf{1 0 0}$ & $\mathbf{1 0 0}$ & $\mathbf{1 0 0}$ & $\mathbf{1 0 0}$ & $\mathbf{1 0 0}$ & $\mathbf{1 0 0}$ & $\mathbf{1 0 0}$ & $\mathbf{1 0 0}$ \\
\hline $\begin{array}{c}\text { Formação centrada nos } \\
\text { conteúdos }\end{array}$ & 48,6 & 68,3 & 67,4 & 63,9 & 67,9 & 74,8 & 67,1 & 74,6 & 71,8 & 56,8 \\
\hline $\begin{array}{c}\text { Formação centrada nos } \\
\text { contextos escolares }\end{array}$ & 51,4 & 31,7 & 32,6 & 36,1 & 32,1 & 25,2 & 32,9 & 25,4 & 28,2 & 43,2 \\
\hline
\end{tabular}

FONTE: Adaptado de CCPFC (2018).

A partir da interpretação dos dados apresentados é possível verificar que de 2010 a 2013 a modalidade "cursos de formação" foi reforçando o seu peso relativo em relação às outras modalidades, verificando-se um decréscimo em $2014 \mathrm{e}$ outro decréscimo mais acentuado em 2017. Apesar desta menor preponderância, os "cursos de formação" permanecem como a modalidade mais utilizada nos últimos anos, contrariamente à realidade de 2008. A segunda modalidade mais utilizada tem sido a "oficina de formação", notando-se, contudo, um registo eminentemente cíclico ao longo dos últimos anos. As restantes modalidades de formação têm tido um papel residual ao nível das políticas formativas. Pela análise do Quadro 1 é ainda possível notar que, nos últimos anos, excetuando mais uma vez o ano de 2008, as ações de formação são fortemente centradas nos conteúdos, em detrimento de uma formação mais centrada nos respetivos contextos escolares. Os dados apresentados corroboram, assim, o exposto por diversos autores, como Forte e Flores (2014), que alertam para a excessiva centralização das ações de formação nos CFAE, relevando a sua pouca ou nula autonomia para criar procedimentos e temáticas nas ações de formação que possam ir ao encontro das reais necessidades de cada escola e professor em particular.

A aposta na formação contínua dos professores, mais ou menos contextualizada, pode contribuir para uma aprendizagem continuada de conhecimentos 
e competências que a formação inicial não consegue proporcionar, para mais nestes tempos de crescente globalização, em que a educação vivencia grandes incertezas que exigem uma grande abertura à mudança. Neste âmbito, Nóvoa (2009) defende a aposta na formação contínua docente como fator decisivo de desenvolvimento profissional docente, particularmente quando esta se centra nos contextos específicos de cada escola e nas legítimas expetativas pessoais de cada professor, não deixando de relevar o trabalho em equipe, o exercício coletivo da profissão e a importância dos projetos educativos de escola.

Tendo presente diversos autores, há que relevar cada vez mais uma formação contínua que possa estar centrada - ou contextualizada - na realidade específica de cada escola, na medida em que esta poderá contribuir, de forma decisiva, para o desenvolvimento profissional dos docentes e, consequentemente, para as melhores aprendizagens dos alunos (MUCHARREIRA, 2016; MUCHARREIRA, 2017). Importa referir que este conceito de formação centrada foi emergindo na década de 90 (HEILBRONN, 1995), entendendo-se por formação centrada na escola todas as iniciativas formativas que dão corpo à política de formação de uma escola, respondendo às suas necessidades específicas. Neste sentido, estando o foco ou até mesmo o local onde decorre a formação, centrada na escola, verifica-se uma mudança de paradigma, pois são os agentes educativos dessa escola que definem as estratégias formativas em função da sua realidade, libertando-se da definição de estratégias estritamente centralizadas pelos organismos centrais (IMBERNÓN, 2006).

Também Ponte. Mata-Pereira, Quaresma e Velez (2014) salientam a importância dos contextos específicos de cada escola, pois podem reforçar práticas colaborativas entre os docentes centradas nos contextos específicos em que estes atuam, capazes de valorizar a investigação e mobilização de situações autênticas da sua prática. Neste enquadramento, os autores sugerem a implementação de ações de formação contextualizadas e que criem uma rutura com os modelos meramente transmissivos e centrados nos conteúdos. A aposta neste tipo de formação e na materialização de práticas colaborativas poderá conduzir à produção de conhecimento praxiológico que se poderá revelar particularmente importante para se conseguir alcançar todo um conhecimento em profundidade do mundo social, possibilitando desta forma a teorização científica a partir da(s) prática(s), a partir dos infindáveis e complexos processos sociais, numa constante relação dicotómica entre o indivíduo e a sociedade (BOURDIEU, 1994).

A formação centrada na escola institucionaliza, assim, no seu contexto, um processo de aprendizagem contínua, perspetivando iniciativas reflexivas e formativas que possibilitam aos professores o questionamento das suas práticas, ganhando estes profissionais um papel reforçado, proativo, deixando de ser encarados como meros recetores para poderem passar a produtores de novos 
saberes através dessa experiência em contexto (SILVA, 2003). Para além deste desenvolvimento profissional docente, existe também a possibilidade de ocorrer uma aprendizagem coletiva de toda a estrutura organizacional (BOLIVAR, 1997).

Ten Dam e Blom (2006) consideram a aposta na formação centrada na escola como uma das mudanças mais significativas e notáveis na história recente da formação de professores, assinalando, em consequência disto, a diminuição da primazia das instituições de ensino superior (IES) na implementação da formação contínua docente, fazendo com que as escolas passem a assumir cada vez mais as suas políticas de formação contínua, nas suas diferentes fases de implementação.

\section{Metodologia}

Em termos metodológicos, a investigação assumiu uma natureza qualitativa, materializada num estudo de caso, seguindo os pressupostos de Bardin (2009), Bogdan e Biklen (1994). A investigação incidiu numa escola privada, da área metropolitana de Lisboa, em Portugal, cuja oferta educativa vai do ensino pré-escolar ao $12 .^{\circ}$ ano (ensino médio), estando matriculados cerca de 1500 alunos no ano letivo de 2013/2014. No mesmo período, o corpo docente era constituído por 106 professores e educadores de infância.

Os instrumentos de recolha de dados consistiram na recolha e análise documental, entrevistas semiestruturadas e a observação direta que permitiu a conceção de notas de campo, entre o ano letivo de 2010/2011 - ano de abertura da escola - e o ano letivo de 2013/2014. Neste artigo, tal como já referido, apresentam-se apenas alguns dados resultantes da recolha e análise documental, concretamente ao nível de determinados documentos estruturantes da organização escolar, como o projeto educativo, o regulamento interno e o plano de formação.

De acordo com Bardin (2009), a recolha e análise documental constitui-se como um conjunto de operações de recolha de documentos que possam facultar informação através de um output diferente do original, procedendo às sínteses ou indexação da informação, tendo por finalidade uma melhor e mais rápida leitura posterior dos dados.

A investigação socorreu-se de recolha e análise documental, mormente no que diz respeito ao projeto educativo e planos de formação dos primeiros quatro anos de funcionamento da escola. Pretendeu-se, assim, aceder a diferentes documentos, procurando compreender quais foram as temáticas, as modalidades, 
a duração, os objetivos e os formadores envolvidos nas ações de formação que foram dinamizadas. Também se perspetivou uma análise alargada e aprofundada ao projeto educativo, tal como se procurou investigar os responsáveis pela sua conceção e implementação, quais os objetivos, e quais as eventuais relações com a política educativa geral. Face ao exposto e seguindo os procedimentos já indicados respeitantes à recolha documental, foi possível com o corpus da investigação definido dar lugar à exploração do material, que por sua vez conduziu à sistematização da informação obtida, tendo em vista a interpretação dos dados recolhidos (Bardin, 2009).

\section{Resultados}

De acordo com a recolha e análise documental, e no que concerne ao projeto educativo da escola onde foi desenvolvida a investigação, foi possível verificar que este se constrói a partir de 4 pilares - a vertente académica, a formação humana, pastoral e atividades de complemento curricular (ACC) -, assente na procura de exercício de uma pedagogia em específico - a pedagogia inaciana, visto ter como patrono um antigo Superior-Geral da Companhia de Jesus - e na construção interdisciplinar de um currículo do mar, conforme é possível constatar na Figura 1.

FIGURA 1 - VERTENTES DO PROJETO EDUCATIVO

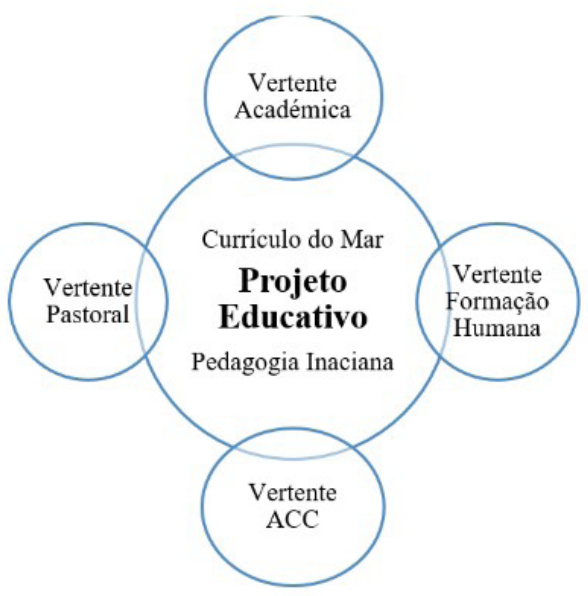


Como se apresenta, o projeto educativo estrutura-se e ao mesmo tempo emerge da designada pedagogia inaciana, onde é proposto um modelo de ensino e de aprendizagem no qual se procura estimular o rigor académico, científico e humanista (TRINDADE; BAHIA; MUCHARREIRA, 2015).

A dinâmica de implementação da pedagogia inaciana, ou paradigma pedagógico inaciano (PPI), passa pela assunção da experiência, reflexão, ação e avaliação, numa constante interação com o contexto em que se insere (STREETMAN, 2015; HOOVER, 2015; TRINDADE; BAHIA; MUCHARREIRA, 2015). Enquadrado num determinado contexto, a pedagogia inaciana pretende instituir uma avaliação constante e dinâmica, assumindo as restantes vertentes, a experiência, a reflexão e a ação. Como foi possível verificar, através da consulta de diferentes documentos, a pedagogia inaciana encontra-se profundamente fundida no projeto educativo, em toda a vida da comunidade escolar, sustentando as práticas de professores, educadores, direção, alunos e funcionários, não deixando, de igual forma, de desafiar os pais e a comunidade envolvente para uma relação próxima, comprometida e interventiva, numa dinâmica permanente de busca e encontro (GRACOS, 1994).

Outro vetor caracterizador do projeto educativo é a sua ligação simbólica ao mar, neste âmbito, é de salientar que surgiu, desde a fundação da escola, a vontade de criar um currículo do mar, transversal e articulado entre todos os ciclos, do pré-escolar ao ensino secundário (ensino médio), destacando-se a organização de uma semana temática alusiva ao mar - sempre na última semana do $2 .^{\circ}$ período -, onde se operacionaliza e se dão a conhecer, a toda comunidade, alguns dos diversos projetos que aí são desenvolvidos (TRINDADE; BAHIA; MUCHARREIRA, 2015).

Este currículo do mar está em linha com uma preocupação crescente dada a estas questões dos oceanos, por parte da sociedade atual, como bem referem Faria, Boaventura, Gaspar, Guilherme, Freire, Chagas e Galvão (2015), embora não se tenha muitas vezes plena consciência das medidas prioritárias para a sua conservação e, ao mesmo tempo, da melhor exploração económica. Neste sentido, os autores defendem a educação como forma de mudar mentalidades e atitudes, sendo um currículo com enormes potencialidades, pois pode ser trabalhado pela generalidade das disciplinas, tal como se perspetiva neste projeto educativo em particular. Esta semana temática alusiva ao mar, em que se efetiva um trabalho assente nas metodologias ativas e na aprendizagem baseada em problemas, constitui-se como uma das atividades estruturantes do plano de atividades anual da escola, reflexo do projeto educativo que o sustenta. No que concerne à política de formação da escola e analisado o plano de formação direcionado aos professores e educadores, constatou-se que este se organiza em quatro níveis, estando-lhes adstrito uma simbologia que remete para a ligação simbólica ao mar. 


\section{FIGURA 2 - REPRESENTAÇÃO SIMBÓLICA DA POLÍTICA DE FORMAÇÃO DA} ESCOLA À LUZ DO PROJETO EDUCATIVO

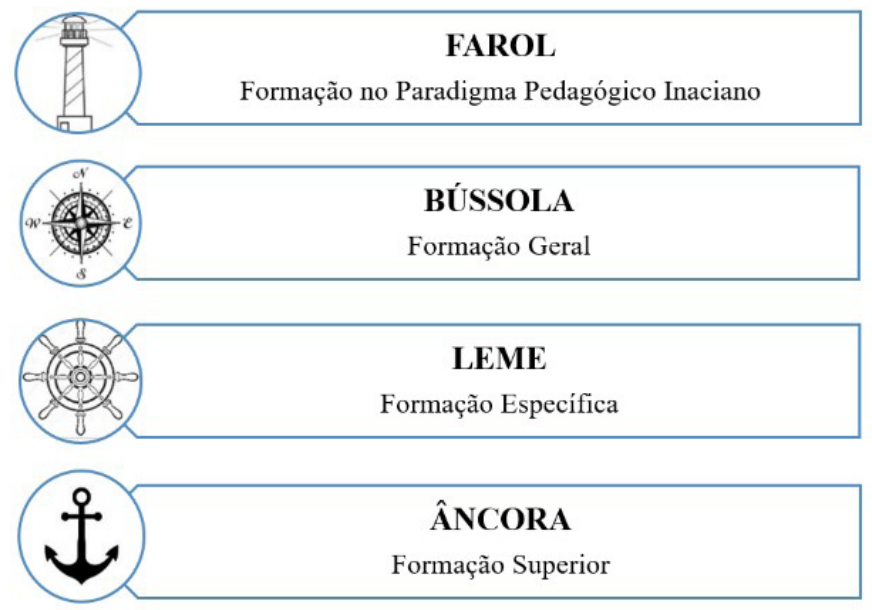

A Formação no Paradigma Pedagógico Inaciano (FPPI) estrutura-se num conjunto de módulos de formação de participação obrigatória que têm como propósito a apropriação pelos docentes dos princípios da pedagogia inaciana que sustenta a globalidade das práticas educativas da escola, sendo assim como que um farol que orienta, ilumina e situa todas as restantes ações de formação.

Quanto à Formação Geral (FG), esta engloba todas as ações de formação, em diferentes modalidades, que não dizem estritamente respeito ao PPI e que se destinam, de igual forma, à participação obrigatória da totalidade dos professores e educadores, perspetivando-se ganhos individuais e grupais, onde todo o trabalho e documentos resultantes das ações de formação possam constituir-se como estruturantes da reflexão e trabalho em sede dos diferentes departamentos. Consecutivamente, espera-se que possam conduzir a melhorias ao nível das práticas letivas dos professores e que estas sejam visíveis positivamente nas aprendizagens dos discentes. Muitas das ações de formação implementadas neste nível são planificadas, implementadas e avaliadas por instituições de ensino superior (IES).

Como o próprio nome sugere, a Formação Específica (FE) diz respeito às ações de formação que são propostas e direcionadas a um departamento curricular em específico ou a uma estrutura em concreto, como as direções de topo ou intermédias, ou os professores responsáveis de turma. Como o plano de formação sugere, sempre que possível, será de privilegiar o recurso a formadores internos, para além de que a ação de formação possa estar de certa forma articulada com as diferentes propostas formativas de caráter geral. 
Por último, a Formação Superior (FS) diz respeito à generalidade de propostas formativas externas à escola, como mestrados, doutoramentos ou participação em projetos de investigação, maioritariamente disponibilizadas pelas IES, tendo naturalmente um caráter facultativo. Através desta participação individual ou em grupo, o plano de formação refere que se deve procurar que os potenciais benefícios resultantes desta formação superior, possam ser, na medida do possível, partilhados com toda a comunidade docente. No Quadro 2 é apresentada a relação do número de ações de formação por ano letivo.

QUADRO 2 - RELAÇÃO DE AÇÕES DE FORMAÇÃO POR ANO LETIVO
\begin{tabular}{|c|c|c|c|c|}
\hline Ano Letivo & $\begin{array}{c}\mathbf{N}^{\mathbf{0}} \text { de Ações de } \\
\text { Formação }\end{array}$ & $\begin{array}{c}\mathbf{N}^{\mathbf{0}} \text { Total de } \\
\text { Formandos }\end{array}$ & $\mathbf{N}^{\mathbf{0}}$ de Horas & $\begin{array}{c}\mathbf{N}^{\mathbf{0}} \text { de Formandos } \\
\text { por Ação }\end{array}$ \\
\hline $2010 / 2011$ & 15 & 636 & 55 & 42 \\
\hline $2011 / 2012$ & 33 & 947 & 139 & 29 \\
\hline $2012 / 2013$ & 46 & 1475 & 150 & 32 \\
\hline $2013 / 2014$ & 41 & 1250 & 149 & 30 \\
\hline Totais & $\mathbf{1 3 5}$ & $\mathbf{4 . 3 0 8}$ & $\mathbf{4 9 3}$ & $\mathbf{3 2}$ \\
\hline
\end{tabular}

FONTE: Mucharreira (2017).

Como é possível verificar, o número de ações de formação realizadas teve um sentido crescente ao longo dos anos letivos, registando um valor máximo de 46 ações de formação em 2012/2013. No ano seguinte verificou-se um ligeiro decréscimo, situando-se nas 41 ações de formação. Acompanhando essa tendência, no que diz respeito ao total de formandos envolvidos, de 1475 participantes nas diferentes ações formativas, registou-se um decréscimo para os $1250 \mathrm{em}$ 2013/2014. Já no que diz respeito ao número de horas, é possível constatar que o decréscimo entre os últimos anos letivos em apreço é pouco significativo.

Tal fato sugere que apesar do ligeiro decréscimo no número de ações de formação entre os anos letivos 2012/2013 e 2013/2014 as ações formativas neste último ano tiveram, contudo, uma duração mais prolongada, totalizando um total de 149 horas, praticamente o mesmo valor registado no ano letivo anterior, neste caso, 150 horas. Realizando-se a ponderação do número total de formandos pelo número de ações realizadas, foi possível constatar que participaram nas ações de formação, no primeiro ano letivo e em média, 42 formandos, reduzindo significativamente no ano subsequente para uma média de 29 formandos, valor que se revelou como o mais baixo dos anos letivos em análise. No ano letivo de 2012/2013 o valor médio voltou a aumentar, para os 32 formandos, voltando a diminuir em 2013/2014, para uma média de 30 formandos por ação. Apesar de estes últimos resultados constituírem uma média, com todas as suas limitações intrínsecas, não deixa de apontar para a existência de algumas ações de formação 
com um grande número de formandos por sessão, o que, à luz das exigências inerentes à acreditação das ações de formação pelo CCPFC, inviabilizaria a acreditação por parte deste organismo, caso tal fosse equacionado.

O Quadro 3 que se segue apresenta a classificação das ações de formação, segundo as modalidades legalmente instituídas, ao longo dos anos letivos.

QUADRO 3 - MODALIDADES DE FORMAÇÃO POR ANO LETIVO - FREQUÊNCIAS ABSOLUTAS E RELATIVAS

\begin{tabular}{|c|c|c|c|c|c|c|c|c|c|c|}
\hline Modalidades & $\mathbf{2 0 1 0 / 2 0 1 1}$ & $\mathbf{\%}$ & $\mathbf{2 0 1 1} / \mathbf{2 0 1 2}$ & $\mathbf{\%}$ & $\mathbf{2 0 1 2 / 2 0 1 3}$ & $\mathbf{\%}$ & $\mathbf{2 0 1 3 / 2 0 1 4}$ & $\mathbf{\%}$ & Total & $\mathbf{\%}$ \\
\hline Curso/Módulo de Formação & 7 & 46,7 & 18 & 54,5 & 27 & 58,7 & 23 & 56,1 & 75 & 55,6 \\
\hline Disciplinas Singulares & 0 & 0,0 & 0 & 0,0 & 0 & 0,0 & 0 & 0,0 & 0 & 0,0 \\
\hline Seminário & 0 & 0,0 & 2 & 6,1 & 2 & 4,3 & 1 & 2,4 & 5 & 3,7 \\
\hline Oficina de Formação & 8 & 53,3 & 13 & 39,4 & 17 & 37,0 & 17 & 41,5 & 55 & 40,7 \\
\hline Estágio & 0 & 0,0 & 0 & 0,0 & 0 & 0,0 & 0 & 0,0 & 0 & 0,0 \\
\hline Projeto & 0 & 0,0 & 0 & 0,0 & 0 & 0,0 & 0 & 0,0 & 0 & 0,0 \\
\hline Círculo de Estudos & 0 & 0,0 & 0 & 0,0 & 0 & 0,0 & 0 & 0,0 & 0 & 0,0 \\
\hline Total & $\mathbf{1 5}$ & $\mathbf{1 0 0} \%$ & $\mathbf{3 3}$ & $\mathbf{1 0 0} \%$ & $\mathbf{4 6}$ & $\mathbf{1 0 0} \%$ & $\mathbf{4 1}$ & $\mathbf{1 0 0} \%$ & $\mathbf{1 3 5}$ & $\mathbf{1 0 0 \%}$ \\
\hline Centrada nos Conteúdos & $\mathbf{7}$ & $\mathbf{4 7} \%$ & $\mathbf{2 0}$ & $\mathbf{6 1} \%$ & $\mathbf{2 9}$ & $\mathbf{6 3} \%$ & $\mathbf{2 4}$ & $\mathbf{5 9 \%}$ & $\mathbf{8 0}$ & $\mathbf{5 9 \%}$ \\
\hline $\begin{array}{c}\text { Centrada nos Processos/ } \\
\text { Contexto Escolar }\end{array}$ & $\mathbf{8}$ & $\mathbf{5 3 \%}$ & $\mathbf{1 3}$ & $\mathbf{3 9} \%$ & $\mathbf{1 7}$ & $\mathbf{3 7 \%}$ & $\mathbf{1 7}$ & $\mathbf{4 1 \%}$ & $\mathbf{5 5}$ & $\mathbf{4 1 \%}$ \\
\hline
\end{tabular}

FONTE: Mucharreira (2017).

Como se pode observar, o ano letivo inaugural da escola, em 2010/2011 foi o único em que a modalidade de oficina de formação teve maior expressão que os cursos/módulos de formação, o que levou, consequentemente, e olhando apenas para a tipificação formal das modalidades segundo o CCPFC, o ano letivo em que as ações de formação se centraram maioritariamente nos processos e contexto escolar (53\%), em detrimento dos conteúdos (47\%). Nos três anos subsequentes, para além da realização pontual de alguns seminários, a modalidade preponderante foram os cursos/módulos de formação, sempre com um peso relativo entre os $55 \%$ e os $58 \%$.

Comparando com os dados apresentados no Quadro 1 e, apesar de algumas limitações com relação aos dados da organização escolar serem apresentados por ano letivo e os do CCPFC (2018) serem relativos ao ano civil, verifica-se que nesta organização escolar, à semelhança das ações de formação acreditadas pelo CCPFC, existe um maior recurso e consequente peso relativo da modalidade curso/módulo de formação, embora de uma forma não tão expressiva. Como se pode verificar, nesta organização escolar o peso relativo situou-se entre os 55\% e $58 \%$ nos últimos três anos, quando, no mesmo período e segundo os dados do CCPFC (2018), o peso relativo desta modalidade se situava entre os $61 \% \mathrm{e}$ $72,7 \%$. Outro dado a reter é o facto de a organização escolar em causa recorrer com maior frequência à modalidade oficina de formação e assim verificar-se um 
reforço percentual na formação centrada nos processos e contextos específicos. Um último dado a ressalvar da análise comparativa é o de se ter verificado uma maior homogeneidade entre os dados gerais e os da organização escolar no período entre 2011 e 2012.

De seguida, no Quadro 4, apresenta-se a relação das ações de formação da organização escolar que foram ou não acreditadas, ao longo dos anos letivos.

\section{QUADRO 4 - ACREDITAÇÃO DAS AÇÕES DE FORMAÇÃO POR ANO LETIVO -} FREQUÊNCIAS ABSOLUTAS E RELATIVAS

\begin{tabular}{|c|c|c|c|c|c|c|c|c|c|c|}
\hline Formação & $\mathbf{2 0 1 0 / 2 0 1 1}$ & $\mathbf{\%}$ & $\mathbf{2 0 1 1 / 2 0 1 2}$ & $\mathbf{\%}$ & $\mathbf{2 0 1 2 / 2 0 1 3}$ & $\mathbf{\%}$ & $\mathbf{2 0 1 3 / 2 0 1 4}$ & $\mathbf{\%}$ & Total & $\mathbf{\%}$ \\
\hline Acreditada & 0 & 0,0 & 1 & 3,0 & 0 & 0,0 & 0 & 0,0 & 1 & 0,7 \\
\hline Não Acreditada & 15 & 100,0 & 32 & 97,0 & 46 & 100,0 & 41 & 100,0 & 134 & 99,3 \\
\hline Total & $\mathbf{1 5}$ & $\mathbf{1 0 0} \%$ & $\mathbf{3 3}$ & $\mathbf{1 0 0 \%}$ & $\mathbf{4 6}$ & $\mathbf{1 0 0 \%}$ & $\mathbf{4 1}$ & $\mathbf{1 0 0 \%}$ & $\mathbf{1 3 5}$ & $\mathbf{1 0 0 \%}$ \\
\hline
\end{tabular}

FONTE: Mucharreira (2017).

É por demais evidente que a quase totalidade das ações de formação (99,3\%), entre 2010/2011 e 2013/2014, não foi acreditada pelo CCPFC, pois, segundo os mesmos registos a que foi possível ter acesso, a não acreditação não ficou a dever-se a uma recusa, mas por não ter sido submetido ao CCPFC qualquer pedido formal de acreditação das ações de formação. Regista-se apenas uma ação de formação acreditada pelo CCPFC, no ano letivo de 2011/2012, e que consistiu, conforme já referido anteriormente, num seminário que teve uma instituição de ensino superior como parceira e responsável pela formação. De seguida, no Quadro 5, são descritas as ações de formação da organização escolar segundo a simbologia adstrita ao projeto educativo, ao longo dos anos letivos. Optou-se por separar a formação "Âncora" das restantes pelo facto de os valores inscritos nesta simbologia dizerem respeito a indivíduos e os valores das restantes simbologias serem respeitantes a ações de formação.

QUADRO 5 - AÇÕES DE FORMAÇÃO DE ACORDO COM A SIMBOLOGIA DO PROJETO EDUCATIVO, POR ANO LETIVO - FREQUÊNCIAS ABSOLUTAS E RELATIVAS

\begin{tabular}{|c|c|c|c|c|c|c|c|c|c|c|}
\hline $\begin{array}{c}\text { Formação } \\
\text { Simbologia }\end{array}$ & $\mathbf{2 0 1 0 / 2 0 1 1}$ & $\mathbf{\%}$ & $\mathbf{2 0 1 1 / 2 0 1 2}$ & $\mathbf{\%}$ & $\mathbf{2 0 1 2 / 2 0 1 3}$ & $\mathbf{\%}$ & $\mathbf{2 0 1 3 / 2 0 1 4}$ & $\mathbf{\%}$ & Total & $\mathbf{\%}$ \\
\hline $\begin{array}{c}\text { Formação } \\
\text { "Farol" }\end{array}$ & 8 & 53,33 & 14 & 42,42 & 5 & 10,87 & 5 & 12,20 & 32 & 23,7 \\
\hline $\begin{array}{c}\text { Formação } \\
\text { "Bússola" }\end{array}$ & 6 & 40,00 & 10 & 30,30 & 12 & 26,09 & 11 & 26,83 & 39 & 28,9 \\
\hline $\begin{array}{c}\text { Formação } \\
\text { "Leme" }\end{array}$ & 1 & 6,67 & 9 & 27,27 & 29 & 63,04 & 25 & 60,98 & 64 & 47,4 \\
\hline Total & $\mathbf{1 5}$ & $\mathbf{1 0 0 \%}$ & $\mathbf{3 3}$ & $\mathbf{1 0 0} \%$ & $\mathbf{4 6}$ & $\mathbf{1 0 0} \%$ & $\mathbf{4 1}$ & $\mathbf{1 0 0 \%}$ & $\mathbf{1 3 5}$ & $\mathbf{1 0 0 \%}$ \\
\hline
\end{tabular}

FONTE: Mucharreira (2017). 
QUADRO 6 - AÇÕES DE FORMAÇÃO DE ACORDO COM A SIMBOLOGIA DO PROJETO EDUCATIVO, POR ANO LETIVO - FREQUÊNCIAS ABSOLUTAS

\begin{tabular}{|c|c|c|c|c|}
\hline Formação Simbologia & $\mathbf{2 0 1 0 / 2 0 1 1}$ & $\mathbf{2 0 1 1 / 2 0 1 2}$ & $\mathbf{2 0 1 2 / 2 0 1 3}$ & $\mathbf{2 0 1 3 / 2 0 1 4}$ \\
\hline Formação "Âncora" & 4 & 4 & 5 & 7 \\
\hline
\end{tabular}

FONTE: Mucharreira (2017).

Nos primeiros dois anos letivos, a designada formação "Farol", respeitante ao paradigma pedagógico inaciano, foi claramente dominante com um peso relativo de $53 \%$ e $42 \%$, perdendo significativamente expressão nos anos subsequentes. No que se refere à formação "Bússola", segunda tipologia mais representativa no primeiro ano letivo, com $40 \%$ do total de ações de formação, foi paulatinamente também perdendo expressão ao longo dos anos letivos, mas de forma menos acentuada que a formação "Farol", verificando-se uma estabilização na ordem dos $26 \%$ de peso relativo, em 2012/2013 e 2013/2014. Já no que diz respeito à formação "Leme", a tendência foi proporcionalmente inversa à das outras duas simbologias, partindo de um peso relativo pouco expressivo na ordem dos $7 \%$ para representar, nos anos letivos 2012/2013 e 2013/2014, entre 60\% e 63\% do total das ações de formação realizadas. Olhando para os valores acumulados, dos quatro anos letivos, verifica-se que quase metade das 135 ações de formação realizadas $(47,4 \%)$ correspondeu a ações de formação "Leme", ou seja, ações de formação específicas a determinadas estruturas, como departamentos, diretores de turma (professores responsáveis de turma) ou chefias intermédias. No que diz respeito à formação “Âncora”, verifica-se uma ligeira evolução de docentes em formação avançada, matriculados em cursos de mestrado ou doutoramento, sendo explicável em grande medida pelo reforço do pessoal docente ao longo dos anos letivos, sendo evidente que em qualquer dos anos letivos em causa, o peso relativo destes docentes em formação avançada, em relação ao total de docentes foi residual, nunca representando mais que $6 \%$ do total de docentes. No Quadro 7 encontra-se discriminada a relação das ações de formação da organização escolar, de acordo com a estrutura que teve a iniciativa de promover as ações de formação, ao longo dos anos letivos.

QUADRO 7 - INICIATIVA DAS AÇÕES DE FORMAÇÃO, POR ANO LETIVO FREQUÊNCIAS ABSOLUTAS E RELATIVAS

\begin{tabular}{|c|c|c|c|c|c|c|c|c|c|c|}
\hline $\begin{array}{c}\text { Iniciativa } \\
\text { Formação }\end{array}$ & $\mathbf{2 0 1 0 / 2 0 1 1}$ & $\mathbf{\%}$ & $\mathbf{2 0 1 1 / 2 0 1 2}$ & $\mathbf{\%}$ & $\mathbf{2 0 1 2 / 2 0 1 3}$ & $\mathbf{\%}$ & $\mathbf{2 0 1 3 / 2 0 1 4}$ & $\mathbf{\%}$ & Total & $\mathbf{\%}$ \\
\hline $\begin{array}{c}\text { Organização } \\
\text { Escolar }\end{array}$ & 14 & 93,3 & 24 & 72,7 & 17 & 37,0 & 16 & 39,0 & 71 & 52,6 \\
\hline Departamentos & 1 & 6,7 & 9 & 27,3 & 29 & 63,0 & 25 & 61,0 & 64 & 47,4 \\
\hline Total & $\mathbf{1 5}$ & $\mathbf{1 0 0} \%$ & $\mathbf{3 3}$ & $\mathbf{1 0 0} \%$ & $\mathbf{4 6}$ & $\mathbf{1 0 0} \%$ & $\mathbf{4 1}$ & $\mathbf{1 0 0} \%$ & $\mathbf{1 3 5}$ & $\mathbf{1 0 0 \%}$ \\
\hline
\end{tabular}

FONTE: Mucharreira (2017). 
Estes resultados corroboram os que foram apresentados anteriormente, pois remetem à evolução crescente do peso dos departamentos enquanto estrutura que, ao longo dos anos letivos, foi dinamizando ações de formação específicas à sua realidade - parte integrante da formação "Leme" -. Ainda assim, no cômputo geral e tendo em consideração os quatro anos letivos, a maioria das ações de formação $(52,6 \%)$ materializou-se através da iniciativa da organização escolar, das suas chefias de topo. Enquanto o quadro anterior dizia respeito à iniciativa da formação, o Quadro 8 que se segue diz respeito à responsabilidade formal de concretização da formação, ou seja, a entidade que concentrou em si as funções de planificação, implementação e avaliação das ações de formação.

QUADRO 8 - RESPONSABILIDADE DAS AÇÕES DE FORMAÇÃO, POR ANO LETIVO - FREQUÊNCIAS ABSOLUTAS E RELATIVAS

\begin{tabular}{|c|c|c|c|c|c|c|c|c|c|c|}
\hline Responsabilidade & $\mathbf{2 0 1 0 / 2 0 1 1}$ & $\mathbf{\%}$ & $\mathbf{2 0 1 1 / 2 0 1 2}$ & $\mathbf{\%}$ & $\mathbf{2 0 1 2 / 2 0 1 3}$ & $\mathbf{\%}$ & $\mathbf{2 0 1 3 / 2 0 1 4}$ & $\mathbf{\%}$ & Total & $\mathbf{\%}$ \\
\hline IES & 6 & 40,0 & 8 & 24,2 & 4 & 8,7 & 11 & 26,8 & 29 & 21,5 \\
\hline $\begin{array}{c}\text { Organização } \\
\text { Escolar/Parceiros }\end{array}$ & 8 & 53,3 & 16 & 48,5 & 13 & 28,3 & 5 & 12,2 & 42 & 31,1 \\
\hline $\begin{array}{c}\text { Departamentos } \\
\text { (Formação Interna/ } \\
\text { Externa) }\end{array}$ & 1 & 6,7 & 9 & 27,3 & 29 & 63,0 & 25 & 61,0 & 64 & 47,4 \\
\hline Total & $\mathbf{1 5}$ & $\mathbf{1 0 0 \%}$ & $\mathbf{3 3}$ & $\mathbf{1 0 0 \%}$ & $\mathbf{4 6}$ & $\mathbf{1 0 0 \%}$ & $\mathbf{4 1}$ & $\mathbf{1 0 0 \%}$ & $\mathbf{1 3 5}$ & $\mathbf{1 0 0 \%}$ \\
\hline
\end{tabular}

FONTE: Mucharreira (2017).

Os resultados acompanham os do quadro anterior, sendo patente o já citado reforço do papel dos departamentos, não apenas na iniciativa, mas na própria implementação da formação. Por outro lado, é possível constatar que o peso relativo da responsabilidade exclusiva das IES foi decrescendo, de uns $40 \%$ em 2010/2011 para 8,7\% em 2012/2013, recuperando em 2013/2014, ano letivo em que a concretização de $26,8 \%$ das ações de formação foram da sua exclusiva responsabilidade. Em seguida, no Quadro 9, é apresentada a relação entre formadores internos e externos relativamente às ações de formação da organização escolar, desenvolvidas ao longo dos anos letivos em apreço.

QUADRO 9 - RELAÇÃO DE FORMADORES INTERNOS E EXTERNOS NAS AÇÕES DE FORMAÇÃO, POR ANO LETIVO - FREQUÊNCIAS ABSOLUTAS E RELATIVAS

\begin{tabular}{|c|c|c|c|c|c|c|c|c|c|c|}
\hline $\begin{array}{c}\text { Relação Formadores } \\
\text { Internos/Externos }\end{array}$ & $\mathbf{2 0 1 0 / 2 0 1 1}$ & $\mathbf{\%}$ & $\mathbf{2 0 1 1 / 2 0 1 2}$ & $\mathbf{\%}$ & $\mathbf{2 0 1 2 / 2 0 1 3}$ & $\mathbf{\%}$ & $\mathbf{2 0 1 3 / 2 0 1 4}$ & $\mathbf{\%}$ & Total & \% \\
\hline Formadores Externos & 6 & 40,0 & 9 & 27,3 & 12 & 26,1 & 15 & 36,6 & 42 & 31,1 \\
\hline Formadores Internos & 9 & 60,0 & 24 & 72,7 & 21 & 45,7 & 16 & 39,0 & 70 & 51,9 \\
\hline $\begin{array}{c}\text { Formadores Externos e } \\
\text { Internos }\end{array}$ & 0 & 0,0 & 0 & 0,0 & 13 & 28,3 & 10 & 24,4 & 23 & 17,0 \\
\hline Total & $\mathbf{1 5}$ & $\mathbf{1 0 0} \%$ & $\mathbf{3 3}$ & $\mathbf{1 0 0} \%$ & $\mathbf{4 6}$ & $\mathbf{1 0 0} \%$ & $\mathbf{4 1}$ & $\mathbf{1 0 0} \%$ & $\mathbf{1 3 5}$ & $\mathbf{1 0 0 \%}$ \\
\hline
\end{tabular}

FONTE: Mucharreira (2017). 
Apesar de se verificar uma evolução gradual, em termos absolutos, do recurso a formadores externos, o que se verifica em termos relativos é um decréscimo entre 2010/2011 (40\%) e 2012/2013 (26,1\%), notando-se uma ligeira recuperação em 2013/2014 (36,6\%). Já no que diz respeito ao recurso a formadores internos, registou-se que, estando em larga maioria nos dois primeiros anos letivos - em grande medida devido à preponderância da formação "Farol" - com $60 \%$ e $72,7 \%$, respetivamente, foi diminuindo o seu peso relativo nos anos letivos subsequentes, não pondo em causa, contudo, a sua preponderância em termos absolutos, com 51,9\% das 135 ações de formação a recorrerem exclusivamente a formadores internos. De relevar que a partir do ano letivo 2012/2013 tiveram início um conjunto de ações de formação que possibilitaram a atuação concertada de formadores externos em parceria com formadores internos, uma parte considerável destes valores correspondendo a uma oficina de formação em específico, designada por "Avaliação das Aprendizagens".

\section{Considerações finais}

Apesar do estudo apresentado ser de natureza qualitativa e suportar-se em resultados referentes a um estudo de caso, o que inviabiliza assim qualquer pretensão generalizadora, não deixa de apontar algumas evidências que podem contribuir para uma maior reflexão destas temáticas.

Os resultados parecem apontar para a existência nesta escola de uma formação centrada na sua realidade, em linha com o defendido por ten Dam e Blom (2006), Nóvoa (2009), Forte e Flores (2014) e Flores (2015), levando ao estabelecimento de uma comunidade de aprendizagem que reflete na e sobre a prática, procurando conduzir um desenvolvimento profissional que possa ter reflexos nas aprendizagens dos alunos (FULLAN, 1991; MUCHARREIRA, 2017). Desta forma, as ações de formação promovidas na organização escolar encontram-se em linha com o projeto educativo, proporcionando espaços de reflexão que potenciam o desenvolvimento profissional dos professores.

O estudo registou ainda evidências que vão ao encontro de Jesus (2000) quando aponta para as oportunidades adstritas à valorização intrínseca das ações de formação, sem a preocupação do formalismo da creditação. Neste caso particular, os principais objetivos que presidiram ao lançamento das ações de formação foram uma perspetiva fundacional de construção da escola e busca pela mudança de práticas com reflexos nas aprendizagens dos alunos, verificando-se uma assinalável implicação docente nas ações que se centraram no designado 
paradigma pedagógico inaciano, numa oficina de formação relativa à reflexão dos critérios de classificação das diferentes disciplinas e em ações que abordavam as questões das necessidades educativas especiais.

De acordo com diferentes documentos da escola, como o plano de formação, a crescente aposta na formação contínua enquanto promotora de reflexão docente e desenvolvimento profissional docente tem justificado a tendência de crescimento do número de ações de formação realizadas na escola ao longo dos anos letivos, refletindo-se consequentemente num acréscimo do número de horas de formação e formandos, apenas com uma ligeira quebra no ano letivo 2013/2014.

Tendo presente a recolha documental efetuada, foi possível constatar também que, embora tivesse sido verificado um significativo recurso a cursos/ módulos de formação na escola, estas ações de formação tendiam a estar, na maioria dos casos, alinhadas com o projeto educativo, com as necessidades e interesses de diferentes instâncias e organismos da escola e seus professores, o que será de relevar, tendo em atenção as potencialidades que daí poderão advir para a escola e todos os seus agentes, tendo em conta o exposto por Nóvoa (2009).

É possível referir ainda que as evidências apontam para um crescente protagonismo dos departamentos curriculares e dos professores em concreto no diagnóstico, implementação e avaliação da formação, aproximando-se do que defendem diversos autores, como Fullan (1992), Gordon, Jacobs e Solis (2014), contribuindo assim para a diluição de lógicas formativas top-down e a emergência das lógicas inversas no diagnóstico, implementação e avaliação da formação contínua. No âmbito das ações de formação em geral, mas também muito especificamente nas ações que contemplaram a existência dos tais grupos reduzidos, a recolha documental evidenciou que é fomentado o desenvolvimento de uma dimensão reflexiva que possibilita a experimentação/aplicação prática, retroalimentando essa reflexão, fazendo emergir um saber profissional sólido e contextualmente coerente.

\section{REFERÊNCIAS}

BARDIN, Laurence. Análise de conteúdo. Lisboa: Edições 70, 2009.

BOGDAN, Robert; BIKLEN, Sari. Investigação Qualitativa em Educação: uma introdução à teoria e aos métodos. Porto: Porto Editora, 1994.

BOLIVAR, Antonio. Liderazgo, mejora y centros educativos. In: MEDINA, Antonio (Org.). El liderazgo en educación. Madrid: UNED, 1997. p. 25-46. 
BOURDIEU, Pierre. Esboço de uma Teoria da Prática. In: ORTIZ, Renato (Org.). $A$ sociologia de Pierre Bourdieu. São Paulo: Editora Ática, 1994.

CANÁRIO, Rui. O que é a Escola? Um “olhar” sociológico. Porto: Porto Editora, 2005.

CANÁRIO, Rui. Centros de Formação das Associações de Escolas: Que Futuro? In: AMIGUINHO, Abílio; CANÁRIO, Rui (Org.). Escolas e mudança: o papel dos Centros de Formação. Lisboa: Educa, 1994.

CCPFC. Relatório de Atividades do Conselho Científico-Pedagógico de Formação Contínua - Relatório de 2017. Braga, Portugal: CCPFC, 2018. Disponível em: $<$ http:// www.ccpfc.uminho.pt/Default.aspx?tabindex $=2 \&$ tabid=20\&pageid=50\&lang=pt-PT $>$.

DIÁRIO DA REPÚBLICA. Decreto-lei n. ${ }^{\circ}$ 127/2015 de 7 de julho. 2015.

FARIA, Cláudia; BOAVENTURA, Diana; GASPAR, Raquel; GUILHERME, Elsa; FREIRE, Sofia; CHAGAS, Isabel; GALVÃO, Cecília. Era Uma Vez... o Mar. O Mar como Recurso Educativo no $1 .{ }^{\circ}$ Ciclo: O contributo do Projeto Ilit. Lisboa: Instituto de Educação da Universidade de Lisboa, 2015.

FLORES. Maria Assunção. Formação de professores: questões críticas e desafios a considerar. In: CNE. Estado da Educação 2014. Lisboa: Comissão Nacional de Educação, 2015.

FORTE, Ana Maria; FLORES, Maria Assunção. Teacher collaboration and professional development in the workplace: a study of Portuguese teachers. European Journal of Teacher Education, v. 37, n. 1, p. 91-105, 2014.

FULLAN, Michael. The New Meaning of Educational Change. Chicago: Teacher College Press, 1991.

GORDON, Stephen; JACOBS, Jennifer; SOLIS, Rachel. Top 10 Learning needs for teacher leaders. Learning Forward, v. 35, n. 6, p. 48-52, 2014.

GRACOS. Pedagogia Inaciana: uma abordagem prática. Braga: Tilgráfica, Sociedade Gráfica, 1994.

HEILBRONN, Ruth. School-based Teacher Training. Can it work? Mentoring \& Tutoring: Partnership in Learning, v. 3, n. 1, p. 62-65, 1995.

HILTON, Gillian; FLORES, Maria Assunção; NIKLASSON, Laila. Teacher quality, professionalism and professional development: findings from a European project. Teacher Development, v. 17, n. 4, p. 431-447, 2013.

HOOVER, Kristin. Reflections on Student Affect in Group Projects: Are We Encouraging Our Students to Be in Community with Others? Jesuit Higher Education, v. 4, n. 1, p. 63-71, 2015.

IMBERNÓN, Francisco. Formação docente e profissional: formar-se para a mudança e a incerteza. São Paulo: Cortez, 2006. 
JESUS, Saúl Neves. Motivação e formação de professores. Coimbra: Quarteto Editora, 2000.

MUCHARREIRA, Pedro Ribeiro; CABRITO, Belmiro Gil; CERDEIRA, Luísa. A formação docente em Portugal: o papel das instituições do ensino superior na formação dos educadores de infância e dos professores do ensino básico e secundário. In: CABRITO, Belmiro Gil (Org.). Ensino Superior no Brasil e Portugal: atualidades, questões e inquietações. Lisboa: Educa, 2018. p. 207-226.

MUCHARREIRA, Pedro Ribeiro. O papel da formação contínua, centrada na escola, na (re) construção do projeto educativo e no desenvolvimento profissional docente: um estudo de caso. Lisboa: Instituto de Educação da Universidade de Lisboa, 2017.

MUCHARREIRA, Pedro Ribeiro. Formação contínua centrada na escola e desenvolvimento profissional docente: um estudo de caso. Educação em Questão, v. 54, n. 42, p. 38-64, 2016.

NÓVOA, António. Para uma formação de professores construída dentro da profissão. Lisboa: Educa, 2009.

PONTE, João Pedro; MATA-PEREIRA, Joana; QUARESMA, Marisa; VELEZ, Isabel. Formação de professores do $1 .^{\circ}$ e $2 .^{\circ}$ ciclos: Articulando contextos de formação e de prática. In: MARTINHO, Maria Helena; TOMÁS FERREIRA, Rosa; BOAVIDA, Ana Maria; MENEZES, Luís (Eds.). Atas do XXV Seminário de Investigação em Educação Matemática. Braga: APM, 2014. p. 155-167.

SILVA, Virgílio Rego. Escola, autonomia e formação. Dinâmicas de poder e lógicas de acção numa escola secundária de Braga. Braga: Instituto de Educação e Psicologia da Universidade do Minho, 2003.

STREETMAN, Heidi. Jesuit Values, Ignatian Pedagogy, and Service Learning: Catalysts for Transcendence and Transformation via Action Research. Jesuit Higher Education, v. 4, n. 1, p. 36-50, 2015.

Ten DAM, Geert; BLOM, Sarah. Learning through participation. The potential of schoolbased teacher education for developing a professional identity. Teaching and Teacher Education, n. 22, p. 647-660, 2006.

TRINDADE, José Pedro; BAHIA, Sara; MUCHARREIRA, Pedro Ribeiro. Uma visão interdisciplinar integrada da Taxonomia de Bloom. In: ESTRELA, Teresa (Ed.). Diversidade e Complexidade da Avaliação em Educação e Formação - Contributos da Investigação. Atas do XXII Colóquio da AFIRSE Portugal. Lisboa: EDUCA/AFIRSE Portugal, 2015. p. 930-942.

Texto recebido em 25 de julho de 2018. Texto aprovado em 15 de agosto de 2018. 